\title{
Table of Orders, Rules and Regulations
}

Act of Sederunt (Rules of the Court of Session 1994) 1994 (SI 1994/1443)

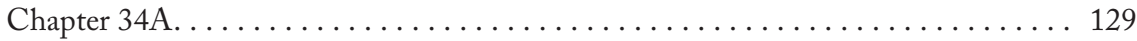

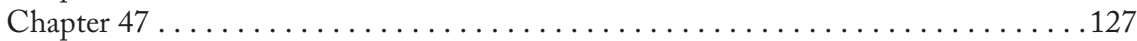

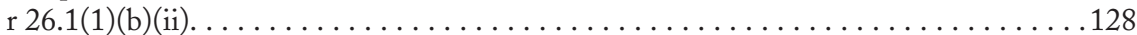

$\operatorname{rr} 47.7,47.12(2)(\mathrm{h})$, (i) . . . . . . . . . . . . . . . . . . . . . . 128

Act of Sederunt (Sheriff Court Ordinary Cause Rules) 1993 (SI 1993/1956)

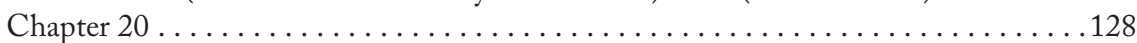

Chapter 27A. . . . . . . . . . . . . . . . . . . . . . . . 129

Bankruptcy (Scotland) Regulations 2014 (SSI 2014/225)

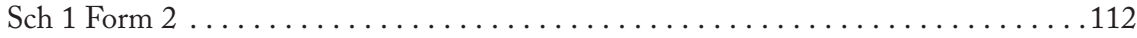

Construction (Design and Management) Regulations 2007

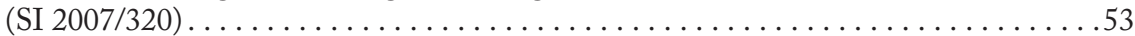

Construction (Design and Management) Regulations 2015

(SI 2015/51) . . . . . . . . . . . . . . . . . . . . . . . . . . . . . . . . 53

Insolvency (Scotland) (Receivership and Winding up) Rules 2018

(SSI 2018/347) . . . . . . . . . . . . . . . . . . . . . . . . . . . 112

Non-Domestic Rating (Unoccupied Property) (Scotland) Regulations 2018

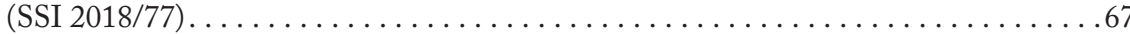

